\title{
Factors influencing the distribution of the bank vole in forest habitats
}

\author{
Maria MAZURKIEWICZ
}

\begin{abstract}
Mazurkiewicz M. 1994. Factors influencing the distribution of the bank vole in forest habitats. Acta theriol. 39: 113-126.

In mosaics of forest environment the bank vole Clethrionomys glareolus (Schreber, 1780 ) prefers patches with dense vegetal cover like understorey or tall herbaceous plants, like ferns or sedges. The size and intensity of the space use, the rate of colonization of free space with population increases and mean home range size are highest in habitats, or their parts, covered uniformly by this type of vegetation. Habitats with dense and uniform understorey characteristically support high vole densities, high numbers of sexually active individuals, high survival rates of individuals entering the population at the beginning of the reproductive season, a high emigration during the second half of the season and a low immigration. Vole populations in habitats of poor and clumped understorey are characterized by low densities, high immigration of individuals entering to the population during the second half of the season and a high turnover of individuals. It has been suggested that vole distribution in a mosaic of forest habitats depends upon the abundance of structural elements of the habitat that may serve as defensive structures against predators.
\end{abstract}

Department of Vertebrate Ecology, Institute of Ecology, Polish Academy of Sciences, Dziekanów Leśny, 05-092 Łomianki, Poland

Key words: Clethrionomys glareolus, habitat structure, space use, demography

\section{Introduction}

The bank vole Clethrionomys glareolus (Schreber, 1780) is an example of a eurytopic species (generalist). It inhabits all types of forest (Hansson 1971, Pucek 1983) and generally dominates numerically amongst woodland rodents (Zejda 1973, Mazurkiewicz and Rajska-Jurgiel 1978, 1987, Banach 1987, 1988 and others). The commonness of the bank vole in the forest mosaic is related to its minimal food requirements, with the dominance of plant food in its diet and its plasticity to use different types of food depending on its availability in various forest habitats (Holišova 1971, Gębczyńska 1983). The polyfagism of voles most likely determines their high site tenacity (Naumov 1951, Nikitina 1970, Mazurkiewicz 1971, but see Andrzejewski and Babińska-Werka 1986) compared to other woodland rodent species (specialists), whose food requirements force them into spacial activity in search of an appropriate food.

In the mosaic forest habitat bank voles are unevenly distributed. This is often associated with varying food abundance of the different habitats (e.g. Kalela 1962, 
Aulak 1970, Hansson 1979). One of the proofs of the influence of food abundance on vole density is the result of experimental increase of the food supply. In such experiment, the vole population underwent a four-fold increase over the density reached with a natural food supply (e.g. Andrzejewski 1975). Studies on large woodland areas do not show dependency on vole density the geobotanic type of the different habitats (Kovalevsky et al. 1971, Kovalevsky and Korenberg 1976, Mazurkiewicz and Rajska-Jurgiel 1978, Jensen 1982, Mazurkiewicz 1984). The vole density in different habitats did not show a dependence on (did not correlate with) the species richness of trees, understorey and herb layer as well as percent cover of that vegetal layer (which determines food abundance) (Mazurkiewicz 1991). It must be therefore assumed that another factor affects the differentiation of vole density in a mosaic forest habitat. Many authors have shown that the density and distribution of bank voles among forest habitats depends on the thickness and type of distribution of such elements of the habitat structure like debris, slash, tall ferns or understorey (Evans 1942, Brown 1956, Lapin 1963, Petrov 1965, Popov 1966, Ivanter 1975, Hansson 1978, Jensen 1982, Wiger 1982, Geuse 1985, Mazurkiewicz 1984, 1986, 1991).

Different structural elements of forest habitats play an important role in the constitution of favorable life conditions for the vole. It seems that the vole's main reason for preferring patches covered with thick, tall vegetation is protection against both predatory birds (Southern and Love 1968) and mammals (Jędrzejewska and Jędrzejewski 1990).

The goal of this study is to answer the question of whether, and, if so, in which ways the thickness and distribution of structural elements of the environment supply shelter and safe movements within the terrain in the different forest habitats, influence space use by the bank vole and the course of demographic processes determining their density in the different habitats.

The present review is based upon original data, published or in preparation, accumulated over the years by the author during studies on bank vole populations in various woodland habitats, by means of the capture-mark-release (CMR) technique. The macroscale habitat structure was characterized using average values of environmental variables (cover and species composition of the different vegetal layers) for the given plot (study area). In the microscale each of the trap sites have been described in detail, including degree of cover and species composition of the vegetation.

\section{Space use by the bank vole}

\section{Size of space utilized}

A method to evaluate the influence of the habitat structure upon the space use by voles consists of measuring the size of the used area (measured as the percent of the trap sites visited by the individuals on the study plot over a given time 
span). In nine selected types of forest in the Piska forest complex $\left(53^{\circ} 40^{\prime} \mathrm{N}\right.$, $\left.21^{\circ} 35^{\prime} \mathrm{E}\right)$, that occur in large patches (10-20 ha), phytosociologically similar but differing in average density of understorey, the size of the area utilized by voles on 1.4 ha plots depended on the density and distribution of understorey. With similar population densities voles utilized larger areas in habitats where dense understorey covered the area uniformly, than in poorer understorey habitats (low average density, clustered distribution). During the seasonal population increase the occupation of free space (increase of percent of trap sites visited) happened faster and reached a higher level in understorey rich habitats (92\% trap sites) than in those with a poorer one (61\% trap sites) with similar population densities (Fig. 1, Mazurkiewicz 1986).

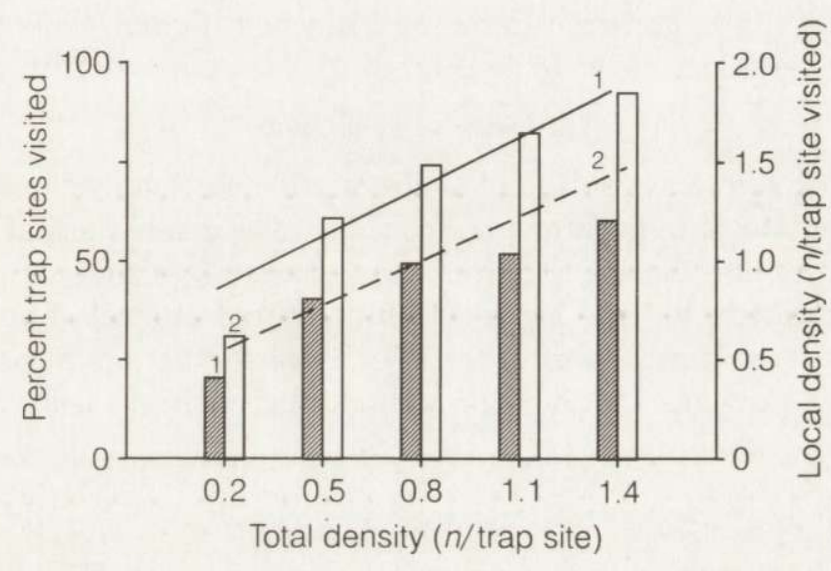

Fig. 1. The dependence of the percent of visited trap sites (bars) and the local density ( $n$ per trap site visited) (lines) on the overall population density (population size/total number of trap sites) in habitats poor (1) and rich (2) in understorey (from Mazurkiewicz 1986, modified).

The avoidance of open areas by the voles, and so without a "protective layer", affected their distribution. Voles with similar densities (number of individuals per trap site), lived in higher local densities (number of individuals per trap site visited) on plots partially covered by understorey than on plots where a more uniformly distributed understorey allowed the voles to occupy the entire area (equalization of total and local densities at the annual peak of vole numbers) (Fig. 1, Mazurkiewicz 1986).

Different size of area utilized by bank voles at similar population density depending on the distribution of the understorey affected the average size of the home range. Voles living in habitats where the understorey was clustered, had smaller and less overlapping home ranges than voles living in habitats with uniform understorey. It seems that in agreement with the data of Pearson (1953) for Peromyscus spp. and Brown (1969) for Apodemus sylvaticus, voles also adapt 
the size of their home ranges to the number of neighbours probably in order to limit the number of direct contacts. An exception would be sexually active females. They had non-overlapping similarly sized home ranges, independent of the understorey distribution (Mazurkiewicz 1986).

The vole's preference of areas with dense understorey, found in the macroscale area of the forest confirm the results of studies on a six hectare plot in the Kampinos National Forest $\left(52^{\circ} 35^{\prime} \mathrm{N}, 20^{\circ} 81^{\prime} \mathrm{E}\right)$. The plot was situated in a fine-grained mosaic of three habitat types (mixed coniferous forest, deciduous forest and a transitional form between them). On this plot data were collected (concerning vegetation cover) for each trap site. Voles during the whole season more readily used the trap sites with dense understorey. During seasonal population increase the occupation of free space (increase in the number of trap sites used) with highest understorey cover $(75 \%)$ occurred faster and reached higher levels than trap sites of the lowest understorey cover (5\%) (Fig. 2, M. Mazurkiewicz, in prep.).

\section{Intensity of space use}

The abundance and distribution of shelters affects not only the size of the area utilized, but also the intensity of use by voles of a given habitat (measured as number of individuals visiting specific trap sites over a given time span). The differentiation of intensity (i.e. aggregation of visited points) of space utilization as a function of the understorey cover, was observed on a six hectare plot (described in the previous section) throughout the entire season. An increase in

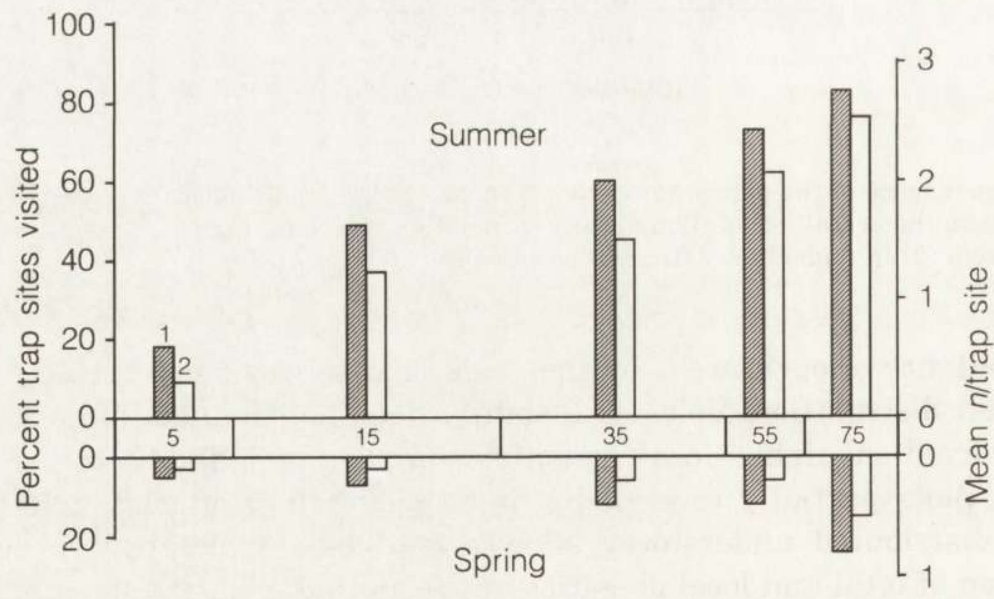

Fig. 2. Influence of the understorey cover on the percent of visited trap sites (1) and the mean number of individuals visiting the trap sites (2) on the 6 ha plot. Trap sites are grouped along the abscissa according to the class of the understorey cover $(5-75 \%)$ in their neighborhood. The lenght of each block represents the proportion of trap sites in that cover class. Spring total $n=19$ individuals (bottom), late summer total $n=130$ individuals (top). Statistical dependence on understorey cover for (1): homogeneity of proportion chi-square (spring: $\chi^{2}=7.1, \mathrm{df}=4, p>0.05$; summer: $\chi^{2}=13.7, \mathrm{df}=4$, $p<0.008$ ), for (2): linear regerssion of number of voles as a function of understorey cover for each trap site (spring: $R^{2}=0.193$, ns; summer: $R^{2}=0.714, p \ll 0.001$ ). (M. Mazurkiewicz, in prep.). 
population density was accompanied by an increase in utilization intensity of all trap sites, but was faster when the percentage cover by understorey in the trap site was higher (Fig. 2). Most voles visited trap sites of the highest understorey cover (75\%) in spite of the fact that these places made up only $12.5 \%$ of the entire plot (of all trap sites). Few voles visited trap sites with the lowest understorey cover ( $5 \%$ of the surface area of the trap site). At high population densities (i.e. in late summer) the average number of individuals per trap site with understorey cover of $75 \%$ and $5 \%$ was 2.5 and 0.3 , respectively (Fig. 2). The utilization intensity of the different parts of the plot was positively correlated with the percent cover of the understorey and also the tall ferns Pteridium aquilinum occurring in patches on the field (Fig. 3). This positive linear correlation was found during analysis of
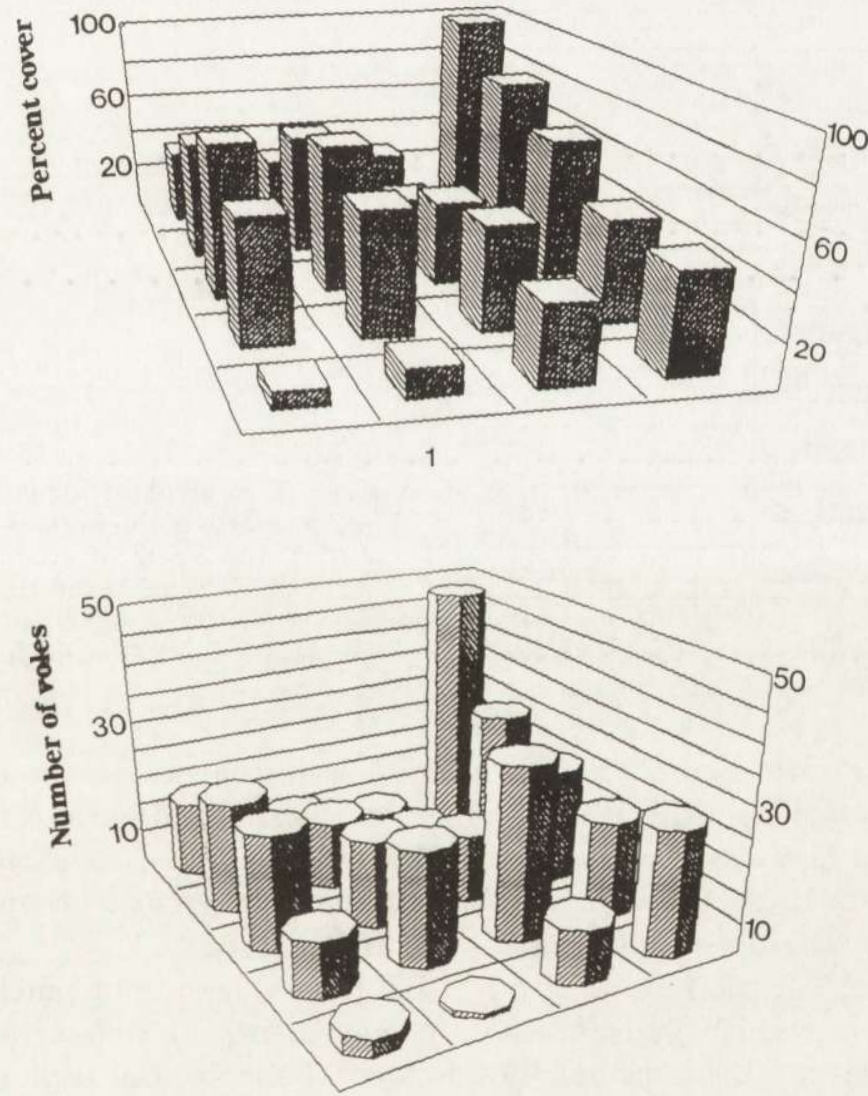

2

Fig. 3. The spatial distribution of the understorey and ferns (1) and the number of captured voles during three years of studies (2) on the 6 ha plot divided into 20 sub-areas (each represents area of 12 trap sites). The relationship between " 1 " and " 2 " $\left(R^{2}=0.449, p<0.003\right)$ was estimated for all trap sites $(n=240)$. (M. Mazurkiewicz, in prep.). 
utilization of both the entire plot and different habitat types occurring on this plot (M. Mazurkiewicz, in prep.). These results suggest that the utilization intensity of a given trap site depends primarily on the safety of movements in the surrounding terrain. It increases along with an increase in the understorey or fern cover.

The above relationship do not only apply inside of forest habitats, but also at the bordrlines between them. The comparison of usage of nine ecotones between the deciduous and alder forests has shown, that the higher the average understorey and sedges density the more voles were captured in the specific ecotones (Fig. 4, M. Mazurkiewicz and E. Rajska-Jurgiel, unpubl.). It can be assumed that the shelter capacity of the border areas between different forest habitats may influence the movements of voles between them.

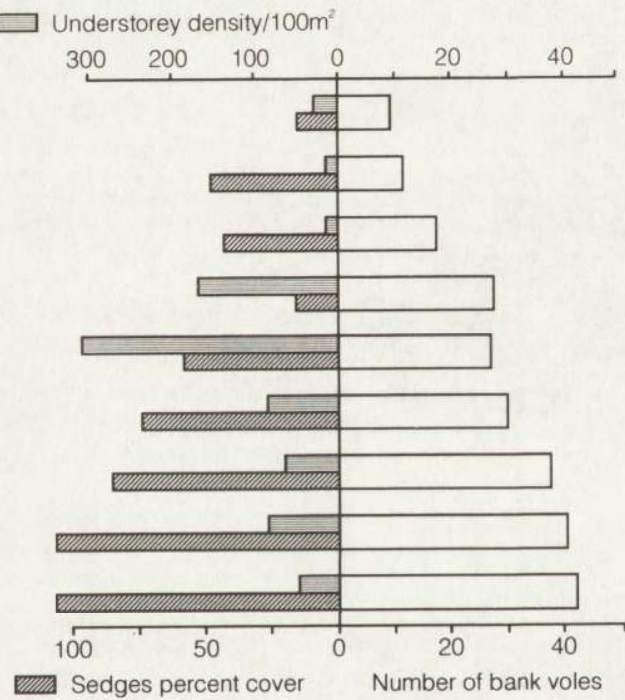

Fig. 4. The number of captured voles in nine ecotones between deciduous and alder forests during two years of studies in relation to understorey density and the area covered by sedges $(\%)\left(R^{2}=0.908, p<0.01\right)$. (M. Mazurkiewicz and E. Rajska-Jurgiel, unpubl.).

The positive influence of the shrub and sapling layers on the distribution of the bank voles and the utilization intensity of the space in various forest habitats was confirmed for other woodland rodent species like Clethrionomys gapperi (Miller and Getz 1972), C. rutilus (Gubar 1974), Peromyscus leucopus (Dueser and Shugart 1978), Microtus longicaudus (Van Horne 1981).

Summarizing, in the mosaic of forest habitats voles prefer patches with thick vegetation cover, which guarantees safe movements in the terrain (protection against predators). This is primarily the layer of shrubs and saplings, but can be from the herb layer, like tall ferns or sedges. The consequences of this preference in pattern of the space use by bank voles, a lack of "desire" to occupy places without protective cover (even at the cost of life in high local densities), a more intensive utilization of patches with a dense shrub and limiting the movements, if it is associated with the necessity of moving in open ground. 


\section{The course of demographic processes}

\section{Density changes}

In accordance with the data presented in the previous section, the abundance and distribution of the shelters may determine the number of places suitable for living by voles. This is suggested by positive relationship between vole density and understorey richness in various habitats (Mazurkiewicz 1984). Seasonal changes in population densities in the different habitats were synchronous. During the entire season the average vole density in understorey rich habitats was higher than in habitats with less developed understorey (Fig. 5). In all habitats

Fig. 5. Seasonal changes in the bank vole density (mean and SD) in habitats poor (1) and rich (2) in understorey (after Mazurkiewicz 1991, modified).

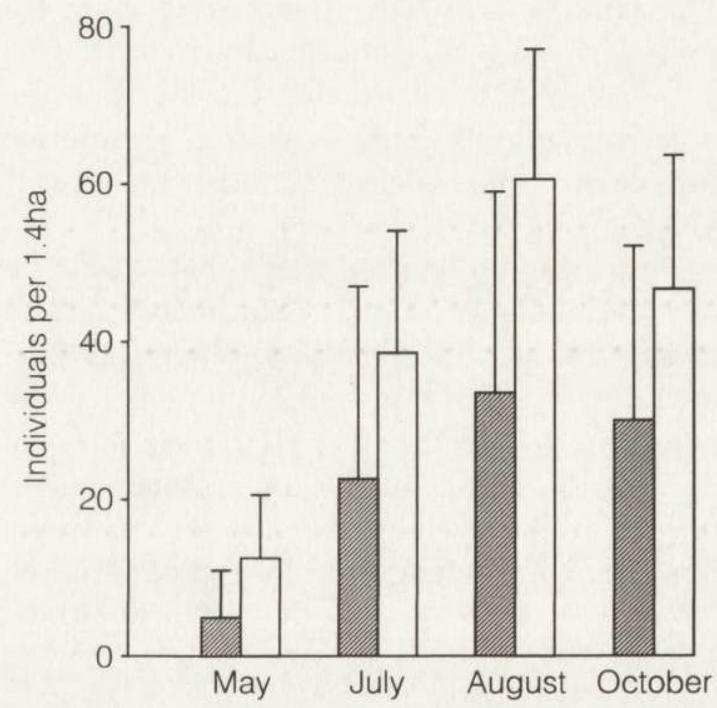

voles attained maximal densities at the same time (end of August). Equalizations of rodent densities between habitats were not observed. Large differences in densities occurred even in neighbouring habitats of similarly aged tree stands and phytosociological types, if they differed drastically in understorey abundance (Mazurkiewicz 1991).

Vole density changes in different habitats during multi-annual cycles were (as in seasonal cycles) synchronous. Differentiation of vole densities in different habitats depending on the understorey abundance, kept up in years of high, as well as low, overall population numbers (Mazurkiewicz 1991).

\section{Numbers of sexually active individuals}

The total density in a given habitat does not always attest to its suitability for rodents (Van Horne 1983). The density of individuals active sexually may be a good indicator of the quality of a given habitat. In understorey rich habitats, the 
average number of sexually active females in a season was almost three times higher than in poorer habitats (21.0-7.8 and 7.5-5.2, respectively). The necessity of supplying itself with satisfactory food and shelter conditions during pregnancy and raising of young cause reproducing females to search and take the optimal places in a given habitat and show territorial tendencies (Naumov 1951, Bujalska 1970) towards other breeding females. The thickness of the understorey may determine the number of places suitable for a breeding territory of an adequate size and not overlapping with the territory of other breeding females. In the different habitats the number of sexually active females did not increase proportionally to the total number of females, and stabilized at a different level, which held the same during the intensive breeding season (July-August), (Fig. 6). The females which were breeding were limited therefore environmentally, and the over- wintering and spring recruited females $(75-97 \%$ of the sexually active females) had the best chances for reproduction. Throughout the entire season, inactive sexually females were a population reserve and could at any time take the place of reproducing females which had disappeared (e.g. death) (Mazurkiewicz 1991).

Limitation of reproduction in the vole population was found by many authors (e.g. Bujalska 1970, 1973, Saitoh 1981). The importance of the protective cover in a habitat is mentioned by Wiger (1982), finding that the habitats with the well-developed shrub and sapling layers are characterized by the most "stable" populations of reproducing females.

The abundance of the understorey affects the density of sexually active males in the different habitats. It seems however, that in contrast to sexually active females, whose density are directly associated with environmental conditions, the factor which affects male density is population density on a given plot. An increase

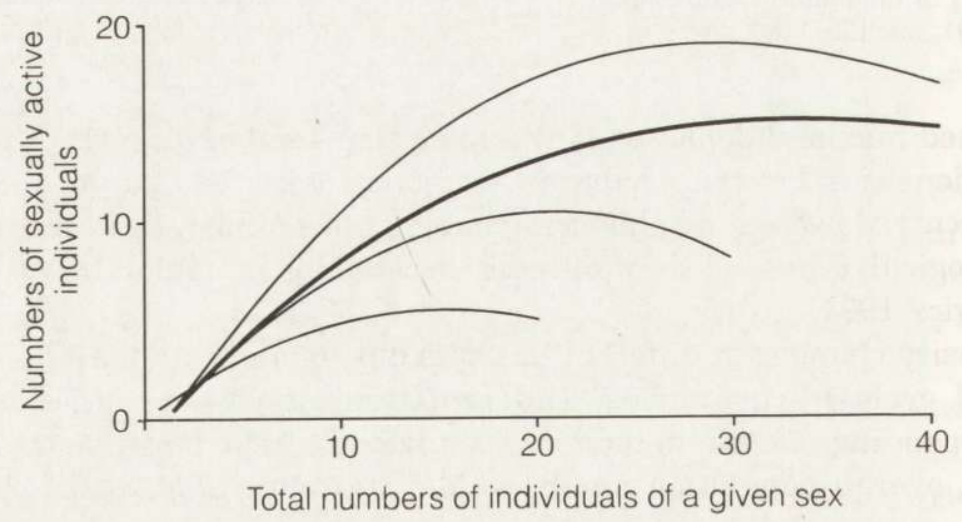

Fig. 6. The relationship between the number of sexually active and the total number of individuals in habitats of different abundance of the understorey. Males 196 thick line, females 196 thin lines. The mean density of the understorey per $100 \mathrm{~m}^{2}$ was: $\mathrm{A}-5.67, \mathrm{~B}-9.13, \mathrm{C}-18.8$. Understorey cover $(\%)$ was: A - 26, B - 100, C - 100. The type of distribution of understorey was: A - clustered, B - random, $\mathrm{C}$ - random. 
in the total density of males (to about 20 per 1.4 ha) was associated with a proportionate increase in the density of sexually active males. Along with a further increase in the total density of males the rate of increase in the density of sexually active males slowed down. And so, in certain habitats (poor understorey) the low density of sexually active males is the effect of low total density of the voles. In habitats characterized by a high total vole density, the density of sexually active males increases initially in proportion to the total number of males, and then stabilizes on a stable level in spite of further increases in the total density of males. The average density of sexually active males is then higher in understorey rich habitats, as compared with understorey poor habitats. The influence of the habitat structure is in this case indirect (via an overall increase in the population density) (Fig. 6).

Sexually active males avoid contact with each other (Rajska-Jurgiel 1976). They also are aggressive to young males, which may lead to inhibition of the latter's sexual maturation (e.g. Watts 1970, Gustafsson et al. 1983, Gustafsson 1985). Aggressive contacts may have a negative influence on the density of sexually active males. On the other hand, the influence of the habitat structure cannot be overlooked. Dense, uniform understorey cover gives better chances of avoiding unwanted contacts. Small and Fairley (1981) demonstrated the positive influence of dense vegetation and complicated soil topography (fissures) on the density of bank vole males.

\section{Recruitment and disappearance of individuals}

Different levels of seasonal density changes in rich and poor understorey habitats can be associated with the different number of sexually active females. The course of the recruitment of individuals (new - unmarked) into a population during the season suggests however, that after a period of fast population increase, when the number of recruits is proportional to the number of overwintering females, a decrease in the recruitment occurs firstly in understorey rich habitats. In the autumn, characterized by low overall recruitment, it is still lower in these habitats, as compared with ones poor in understorey (Fig. 7). During the entire season the average number of recruits per sexually active female is higher in understorey poor habitats (July $-10.2 \pm 5.1$, August $-5.1 \pm 3.9$, October $-4.0 \pm$ $4.0)$ than in rich ones ( $7.7 \pm 5.6,3.1 \pm 2.1,1.8 \pm 0.6$ respectively). The differences in recruitments rates increase from spring until autumn (Mazurkiewicz 1991).

Habitats rich and poor in understorey also vary as far as disappearance is concerned. The differences are only amongst the sexually inactive individuals. The disappearance of sexually active individuals was independent of the moment of entry into the population ( $41 \%$ and $48 \%$ disappeared early and late summer respectively). In understorey rich habitats low disappearance rates was a characteristic of voles recruited the population at the beginning of the summer $(39 \%$ 


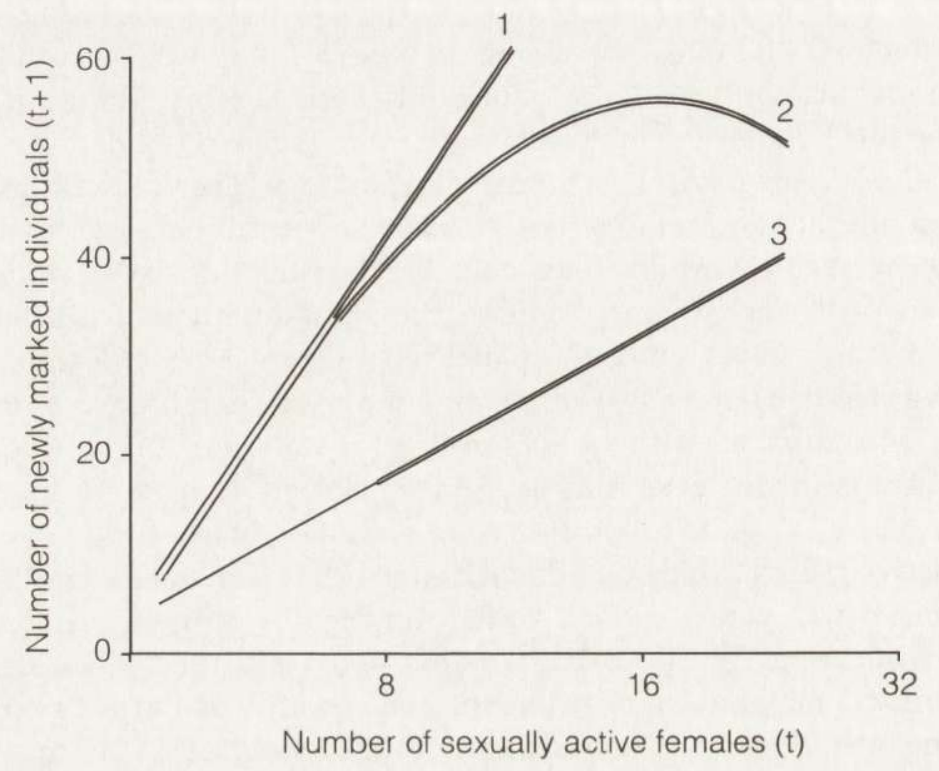

Fig. 7. The relationship between the number of recruits in July (1), August (2) and October (3) and the number of sexually active females in the previous period (May, July and August, respectively). On each curve the parts on which were located the data from poor in understorey habitats were marked by single lines, and from reach ones by double lines (scheme by Mazurkiewicz 1991).

disappeared by the next series of trapping), however, disappearance rates of voles marked during the second half of the summer was very high $(66 \%)$. In understorey poor habitats disappearance rates of voles was high throughout the entire season (51\% and 58\% early and late summer respectively) (Mazurkiewicz 1991).

The decrease in the recruitment, in spite of high numbers of breeding females and an increase of disappearance rates during the second half of the summer in understorey rich habitats, suggests that their saturation occurs already in the early-summer, and individuals born in a later period most likely emigrate to other habitats, probably poor in understorey. High recruitment in those habitats in late summer and autumn are proof of this. However low residency possibilities in understorey poor habitats limited appropriately to the area suitable for living, forces voles to further searching for places to reside, and in effect high disappearance is noted throughout the entire season. That leads to a high turnover of voles in those habitats.

The residency of voles in their place of birth depends on the shelter capacity and the moment of recruitment The decrease of the recruitment rates during the season may then be associated with a decrease in the vacant space, suitable for living and, associated with that, a decrease in the chances of voles residing on that given area. During the late summer and autumn the number of recruits (unmarked) per sexually active female in the different habitats depends on the 
Fig. 8. The relationship between the number of recruits in the second half of the season per sexually active female and the number of persisting voles. Habitats are marked as understorey poor or rich (see Fig. 7, after Mazurkiewicz 1991, modified).

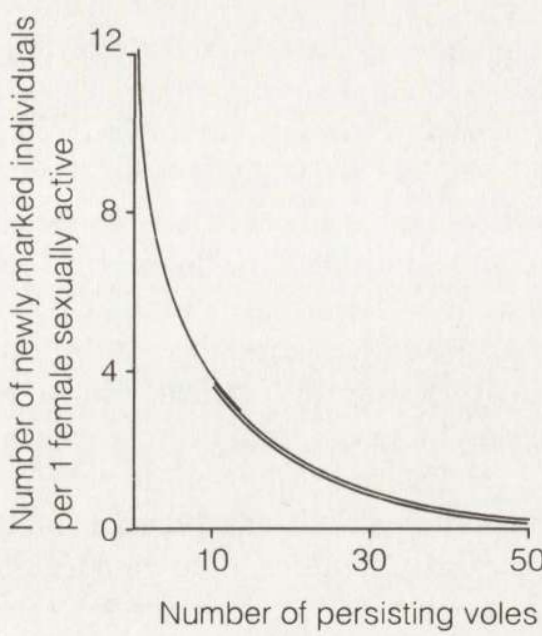

actual density of the population, and so on the persistence of the individuals, which entered the population earlier. That is usually higher in understorey rich habitats (Fig. 8). The high degree of residency at the beginning of the season in understorey rich habitats causes the population structure in those habitats to be "older" in comparison to understorey poor habitats.

Habitats rich in understorey are survival habitats sensu Anderson (1980) for the bank vole. They are characterized by high densities, high numbers of sexually active individuals, high survival rates of spring recruits and so primarily voles which form reproductive base. High emigration during the second half of the season and low immigration are also observed. Understorey poor habitats are colonizing ones (Anderson 1980) of low density, of high numbers of recruits during the second half of the season which is caused by high immigration rather than local reproduction and high turnover of individuals.

\section{Summary}

1. In the mosaic of forest habitats the voles prefer patches of dense plant cover, forming the protective layer against predators. That preference is one of the basic factors influencing the uneven distribution of vole densities in the forests mosaic, observed by many researchers. In various parts of the same forest habitat vole density may differ very much, depending on the abundance and spatial distribution of those elements of the habitat structure, which provide shelter. In habitats phytosociologically different but similar in respect to density and distribution of the sheltering elements, the vole density may be similar.

2. The distribution of the understorey (or structural elements of the habitat which have a protective function) influences the way the space is used by voles. 
The size of the utilized area and the rate of occupation of free space along with the seasonal density increase are higher in habitats, or their parts, uniformly covered in understorey. Similarly, in fine-grained mosaics of different habitats the rate of occupation places covered with dense understorey and the intensity of their utilization is higher than in open places, independent of the phytosociological type of the habitat. This leads to a differentiation in the local densities between the patches with dense and sparse understorey. Avoidance of open places affects the mean home range size. It is lower in habitats with understorey distributed in clusters than in habitats where the understorey uniformly covers the area. In both cases however, individuals retain similar zones of intercontact.

3 . The main parameter which differentiates parts of the vole population living in understorey rich and poor habitats is the number of sexually active individuals, primarily females. The density and distribution of the understorey determine the number of places suitable for the establishment of reproductive territories by the females, which do not overlap with the territories of other breeding females. In understorey rich habitats, almost three times more sexually active females can reside on the same area than in poorer ones. However, shelter conditions do not affect the degree of residency of sexually active individuals and in the case of females, the size of home ranges and the degree of their overlapping.

4. Different numbers of sexually active females indicate the different reproductive intensity in understorey rich and poor habitats. The ability of residency in the place of birth depends on the food and shelter conditions of the given habitat and the time of recruitment. Saturation of space suitable for living occurs already in the early summer. In habitats uniformly covered with a protective layer, thanks to uniform living conditions, the entire area is colonized by voles born at the beginning of the season. So those born in later periods are forced to emigrate. Habitats of varying living conditions (only part of the area is covered by understorey) are colonized locally by only a small number of individuals born on a given area, the majority being immigrating individuals, which left saturated, better habitats and are searching for places suitable for living.

\section{References}

Anderson P. K. 1980. Evolutionary implications of microtine behavioural system on the ecological stage. The Biologist 62: 70-88.

Andrzejewski R. 1975. Supplementary food and winter dynamics of bank voles populations. Acta theriol. 20: 23-40.

Andrzejewski R. and Babińska-Werka J. 1986. Bank vole populations: are their densities really high and individual home ranges small? Acta theriol. 31: 407-420.

Aulak W. 1970. Small mammal communities of the Białowieża National Park. Acta theriol. 15: 465-515.

Banach A. 1987. Small rodent communities in a complex forest biotops. Acta theriol. 32: 229-244.

Banach A. 1988. Population of the bank vole in the mosaic of forest biotops. Acta theriol. 33: 87-102. 
Brown L. E. 1956. Field experiments on the activity of the small mammals Apodemus, Clethrionomys and Microtus. Proc. zool. Soc., London: 126: 549-564.

Brown L. E. 1969. Field experiments on the movements of Apodemus sylvaticus L. using trapping and tracking technique. Oecologia 2: 198-222.

Bujalska G. 1970. Reproduction stabilizing elements in an island population of Clethrionomys glareolus (Schreber, 1780). Acta theriol. 15: 381-412.

Bujalska G. 1973. The role of spacing behaviour among females in the regulation of the reproduction in bank vole. J. Reprod. Fert., Suppl. 19: 465-474.

Dueser R. D. and Shugart M. H., Jr 1978. Microhabitats in a forest floor small-mammal fauna. Ecology 59: 89-98.

Evans F. C. 1942. Studies of a small mammal population in Bagley Wood, Berkshire. J. Anim. Ecol. 11: $182-197$.

Gębczyńska Z. 1983. Feeding habits [In: Ecology of the bank vole. K. Petrusewicz, ed]. Acta theriol. 28, Suppl. 1: 40-49.

Geuse P. 1985. Spatial microhabitat of bank voles and wood mice in a forest in central Belgium. Acta zool. Fenn. 173: 61-64.

Gubar J. P. 1974. Stacjii krasnoj polevki (Clethrionomys rutilus Pall.) Onežskogo pouostrova. Fauna i Ecol. Živ. Nauka, Moskva: 174-188.

Gustafsson T. O. 1985. Sexual maturation in Clethrionomys. Ann. zool. fenn. 22: 303-308.

Gustafsson T. O., Anderson C. B. and Nyholm N. E. J. 1983. Comparison of sensititivity to social suppresion of sexual maturation in captive male bank voles, Clethrionomys glareolus originating from populations with different degrees of cyclicity. Oikos 41: 250-254.

Hansson L. 1971. Small rodent food, feeding and population dynamics. A comparison between granivorous and herbivorous species in Scandinavia. Oikos 22: 183-198.

Hansson L. 1978. Small mammal abundance in relation to environmental variables in three Swedish forest phases. Stud. Forest. Snee. 147: 5-39.

Hansson L. 1979. Condition and diet in relation to habitat in bank voles Clethrionomys glareolus: population or community aproach? Oikos 33: 55-63.

Holišova V. 1971. The food of Clethrionomys glareolus at different population dynamics. Acta Sci. nat. Brno 5; 11: 1-43.

Ivanter E. V. 1975. Populacjonnaja ekologija melkih mlekopitajuščih taežnovo severo-zapada SSSR. Izd. Nauka, Leningrad: 1-246.

Jensen T. S. 1982. Habitat distribution, home range and movements of rodents in mature forest and reforestation. Acta. zool. Fenn. 171: 305-307.

Jędrzejewska B. and Jędrzejewski W. 1990. Antipredatory behaviour of bank voles and prey choice of weasels - enclosure experiments Ann. zool. fenn. 27: 321-328.

Kalela O. 1962. On the fluctuations in the numbers of arctic and boreal small rodents as a problem of production biology. Ann. Acad. Sci. Fenn., Ser. A. IV. Biol. 66: 1-38.

Kovalevsky J. V., Karpenko E. I. and Katenina N. D. 1971. Methods for large-scale mapping of the distribution and abundance of small forest rodents. Fauna i Ekologija Gryzunov 10: 172-186. [In Russian with English summary]

Kovalevsky J. V. and Korenberg E. I. 1976. The determination of the norm of quantitative accounts of forest Muridae under the large-scale mapping of their distribution. Zool. Ž. 7: 1079-1085. [In Russian with English summary]

Lapin J. M. 1963. Biologija i parazitofauna melkih lesnyh mlekopitajuščih Latvijskoj SSR. Izd. AN LSSR, Riga: 1-135.

Mazurkiewicz M. 1971. Shape, size and distribution of home range of Clethrionomys glareolus . (Schreber, 1780). Acta. theriol. 16: 23-60.

Mazurkiewicz M. 1984. Population density of small rodents as affected by chosen elements of tree stand structure. Bull. Acad. Pol. Sci., Cl II 32: 209-217. 
Mazurkiewicz M. 1986. The influence of undergrowth distribution on utilization of space by bank vole populations. Acta theriol. 31: 55-69.

Mazurkiewicz M. 1991. Population dynamics and demography of the bank vole in different tree stands. Acta theriol. 36: 207-227.

Mazurkiewicz M. and Rajska-Jurgiel E. 1978. Size and structure of rodent community of various forest stand types. Bull. Acad. Pol. Sci., Cl II 10: 669-677.

Mazurkiewicz M. and Rajska-Jurgiel E. 1987. Numbers, species composition and residency of a rodent community in forest and field-forest ecotones. Acta theriol. 32: 413-432.

Miller D. H. and Getz L. L. 1972. Factors influencing the local distribution of the red backed vole Clethrionomys gapperi in New England. Univ. Connecticut. Occas. Papers, Biol. Sci. Ser. 2: $115-138$.

Naumov N. B. 1951. Novyj metod izučenija ekologii melkih lesnyh gryzunov. Fauna i Ekologija Gryzunov 4: 3-21.

Nikitina N. A. 1970. On permanency in the use of territories by rodents. Fauna i Ecologija Gryzunov 9: 110-134. [In Russian with English summary]

Pearson P. G. 1953. A field study of Peromyscus population in Gulf Hammock, Florida. Ecology 34: 199-207.

Petrov O. V. 1965. Značenie lesnyh ovragov v žyzni myševidnyh gryzunov lesostepnyh dubrav. Vest. Leningr. Univ. Biol. 9: 26-32.

Popov V. A. 1966. Mlekopitajuščije Volzsko-Kamskogo Kraja. Izd. AN SSSR, Kazanskij Filial, Kazan: 1-467.

Pucek M. 1983. Habitat preference. [In: Ecology of the bank vole. K. Petrusewicz, ed]. Acta theriol. 28, Suppl. 1: 31-40.

Rajska-Jurgiel E. 1976. Interactions between individuals of a population of the bank vole Clethrionomys glareolus (Schreber, 1780). Ecol. pol. A 24: 3-35.

Saitoh T. 1981. Control of female maturation in high density populations in the red backed Clethrionomys rufocanus bedfordiae. J. Anim. Ecol. 50: 79-87.

Smal C. M. and Fairley J. S. 1981. The dynamics and regulation of small rodent population in the woodland ecosystems of Killarney. Ireland. J. Zool., Lond. 196: 1-30.

Southern M. N. and Lowe V. P. W. 1968. The pattern of distribution of prey and predation in tawny owl territories. J. Anim. Ecol. 37: 75-97.

Van Horne B. 1981. Demography of Peromyscus maniculatus populations in several stages of coastal coniferous forest in southeast Alaska. Can. J. Zool. 59: 1045-1961.

Van Horne B. 1983. Density as a misleading indicator of habitat quality. J. Wildl. Manage. 47: 893-901.

Watts C. H. S. 1970. A field experiment on intraspecific interaction in the red-backed vole Clethrionomys gapperi. J. Mammal. 51: 331-347.

Wiger R. 1982. Roles of self regulatory mechanisms in cyclic populations of Clethrionomys with special reference to C. glareolus, a hypothesis. Oikos 38: 60-71.

Zejda J. 1973. Small mammals in certain forest type groups in southern Moravia. Zool. Listy 22: 1-13.

Received 6 March 1992, revised 9 March 1994, accepted 9 March 1994. 